\title{
The dynamic distribution of duck Tembusu virus in the spleen of infected shelducks
}

\author{
Xuejing Sun, Enxue Liu, Adeela lqbal, Taozhi Wang, Xindong Wang, Abdul Haseeb, Nisar Ahmed, Ping Yang and \\ Qiusheng Chen
}

\begin{abstract}
Background: Duck Tembusu virus (DTMUV) is a novel member of Flavivirus. The isolated and purified DTMUV strain XZ-2012 was used as a strain model, to intramuscularly inject the six-month egg-laying shelducks with the infective dose of $10^{4} \mathrm{TCID}_{50}$. The dynamic distribution of the virus in spleen at different time post-infection (pi) was studied using RT-PCR, RT-qPCR, ELISA, immunofluorescence and transmission electron microscopy (TEM).

Result: The results showed that the virus occurred in the spleen after 2 hpi and lasted up to $18 \mathrm{dpi}$. The registered viral load increased from $2 \mathrm{hpi}$ to $3 \mathrm{dpi}$, and then it diminished from $6 \mathrm{dpi}$ to $18 \mathrm{dpi}$ with a slight rise at $12 \mathrm{dpi}$. From 2 hpi to 6 dpi the DTMUV particles were mostly distributed in the periellipsoidal lymphatic sheath (PELS) of spleen white pulp, few being found in the sheathed capillary. From 9 dpi to $18 \mathrm{dpi}$, the DTMUV particles were migrating into periarterial lymphatic sheaths (PALS) around the central artery through the red pulp. Under TEM, the virus particles could be observed mostly in lymphocytes and macrophages.

Conclusion: It was suggested that DTMUV invaded lymphocytes and macrophages of the spleen at $2 \mathrm{hpi}$ and replicated significantly from 1 dpi to 3 dpi, being eliminated from 9 dpi to $18 \mathrm{dpi}$. This is the first study on the dynamic distribution of DTMUV from invasion to elimination in duck spleen conducted by molecular and morphological methods. It could provide theoretical basis for the occurrence, development and detoxification of the virus in the organs of the immune system.
\end{abstract}

Keywords: Duck Tembusu virus, Spleen, Dynamic distribution

\section{Background}

In April 2010, an infectious disease of egg-laying ducks outbroke in the region of southeastern coastal provinces of China, caused by a novel type of Flavivirus infection, named duck Tembusu virus (DTMUV) [1-5]. DTMUV is a positive sense single-stranded RNA enveloped virus from Flavivirus genus, Flaviviridae family. The DTMUV genome is approximately $11 \mathrm{~kb}$ in length, consisting of a 5 '-terminal non-coding region and a 3 '-terminal noncoding region and a middle open reading frame. This open reading frame encodes 3 structural proteins: the capsid protein $(\mathrm{C})$, the membrane protein precursors $(\operatorname{PrM})$ and the envelope protein (E), and 7 non-structural proteins (NS1, NS2A, NS2B, NS3, NS4A, NS4B and NS5) $[6,7]$. The envelope protein is the main structural protein

\footnotetext{
* Correspondence: chenqsh305@njau.edu.cn

Ministry of Education Joint International Research Laboratory of Animal

Health and Food Safety, College of Veterinary Medicine, Nanjing Agricultural University, Wei gang No.1, Nanjing 210095, Jiangsu Province, China
}

that forms the virus envelope and contains multiple epitopes, being the main antigen protein that triggers the host's immune response [8]. The mature virion could be observed by transmission electron microscopy (TEM), having the nucleic acid in the center and an envelope with the diameter of 40 to $60 \mathrm{~nm}$ [9]. There is a high homology among various DTMUV strains and other Flaviviruses [10].

DTMUV exhibits a wide range of natural host species, including egg-laying ducks [3], meat-type ducks [11, 12], chickens [13, 14], geese [15-17] and mice [18, 19], etc. Moreover, it can proliferate in duck embryo, chicken embryo, duck and chicken embryo fibroblast, baby hamster kidney cell 21 (BHK-21) and Vero cell [20]. At present, the common diagnostic methods used in the laboratory are serological tests such as enzyme-linked immunosorbent assay (ELISA) [21], the neutralization test, and the molecular biological methods such as reverse transcription-polymerase chain reaction (RT-PCR),

(c) The Author(s). 2019 Open Access This article is distributed under the terms of the Creative Commons Attribution 4.0 International License (http://creativecommons.org/licenses/by/4.0/), which permits unrestricted use, distribution, and 
reverse transcription-loop-mediated isothermal amplification (RT-LAMP) and real-time quantitative polymerase chain reaction (RT-qPCR) [22].

Flaviviruses Can lead to viremia through vascular system and accumulate firstly into the spleen [23-25]. The spleen exhibited higher viral loads compared to other organs $[22,26]$. In birds, the spleen is the largest secondary lymphatic organ and plays an important role in restraining the circulating pathogens. The duck spleen composes of white pulp and red pulp without marginal zone. The red pulp consists of splenic cord and splenic sinus. The white pulp is composed of circular ellipsoids around the sheathed capillary that has cuboidalshaped endothelial cells, periellipsoidal lymphatic sheaths (PELS), periarterial lymphatic sheaths (PALS) around the central artery, and splenic nodules. The ellipsoid consisted of several layers of supporting cells. In particular, the duck spleen has a blood-spleen barrier (BSB), as a kind of immune barrier [27]. Whether BSB blocks the spreading of DTMUV, affecting its dynamic distribution, it is still unclear. In this experiment, the isolated and purified strain XZ-2012 was used as strain model, and the changes in virus distribution and content in infected duck spleen from invasion to elimination was investigated. It could provide a theoretical basis for the dynamic distribution of this virus in the immune organ and the relationship between the virus and the immune barrier.

\section{Results}

\section{DTMUV strain XZ-2012 amplification}

RT-PCR products of duck embryo allantois fluid were detected by agarose gel electrophoresis. The positive band size was approximately $249 \mathrm{bp}$, which was in accordance with the expected size (Fig. 1). Hyperemia and hemorrhage were present in the whole body of the infected duck embryos (Fig. 2).

\section{DTMUV TCID 50}

The $\mathrm{TCID}_{50}$ results were calculated using the Reed-Muench method. TCID 50 was $10^{4.7} / \mathrm{mL}$.

\section{Qualitative detection of DTMUV in blood and spleen}

RT-PCR products of duck blood and spleen were detected by agarose gel electrophoresis. It was found that the DTMUV was present in blood from 1 hpi to 18 dpi, and in spleen from 2 hpi to $18 \mathrm{dpi}$. The control group was negative (Fig. 3). The results of the qualitative ELISA were consistent with those of RT-PCR.

\section{Quantitative detection of DTMUV in the spleen $R T-q P C R$}

XZ-2012 virus concentrations in the spleen were calculated according to a standard curve that had a linear

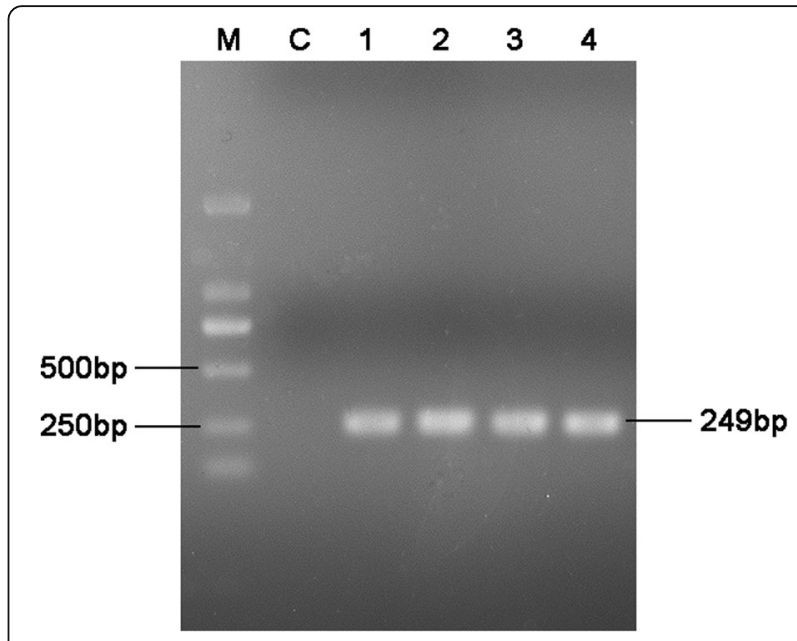

Fig. 1 RT-PCR results of duck embryos allantoic fluid. M: DL 2000 bp DNA marker; C: Duck embryo allantoic fluid of control; 1-4: Duck embryo allantoic fluid of treatment

relationship with $\mathrm{Ct}$ value in the range from $10^{3}$ copies to $10^{8}$ copies. The results showed that the $\mathrm{Ct}$ value and the number of copies from 2 hpi to $18 \mathrm{dpi}$ were all in the detectable range. The number of viral genes copies increased slowly between $2 \mathrm{hpi}$ and $12 \mathrm{hpi}$, and significantly at $1 \mathrm{dpi}$ and $3 \mathrm{dpi}$, then rapidly decreased, while registered a slight rise at $12 \mathrm{dpi}$. The number of copies at $1 \mathrm{hpi}$ and 24 dpi was too low to be detected (Fig. 4).

\section{Elisa}

The concentrations of XZ-2012 strain in the spleen from 2 hpi to 18 dpi were detected by ELISA, which showed a similar change trend to that of the viral gene. The virus concentration was increasing between $2 \mathrm{hpi}$ and $3 \mathrm{dpi}$

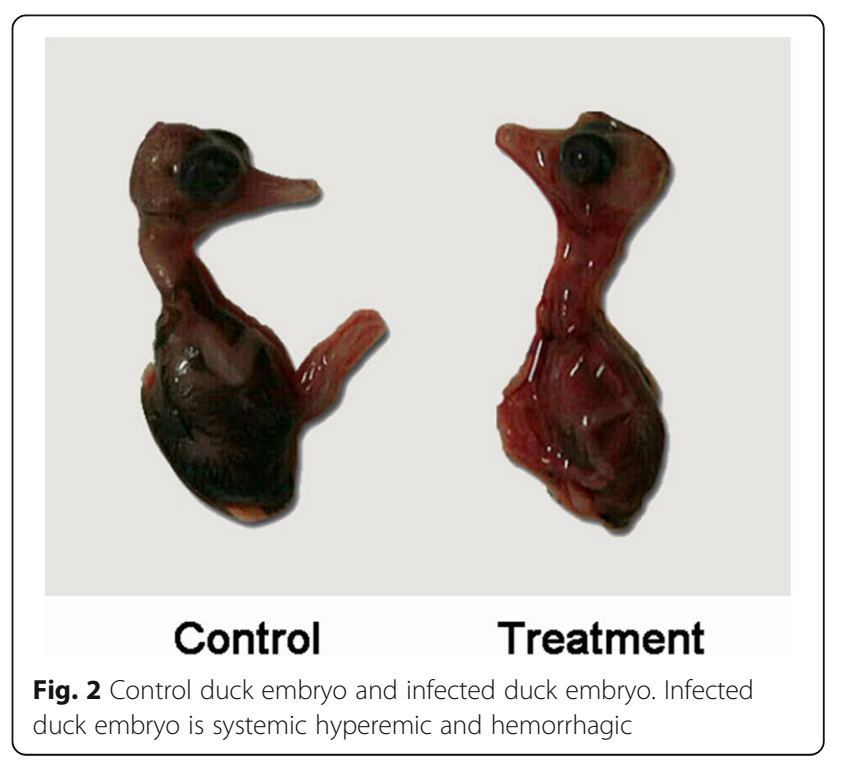




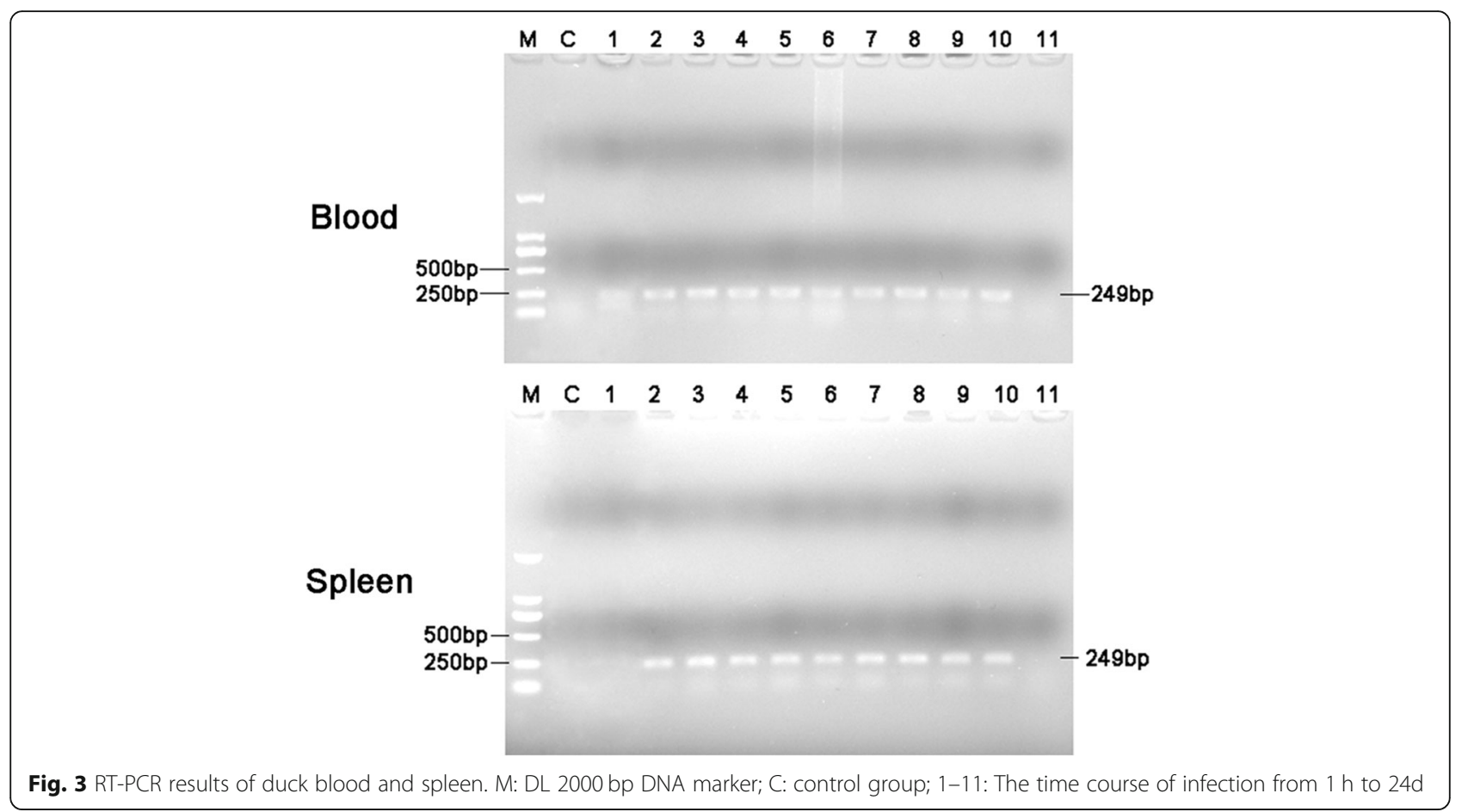

and reached the highest level at $3 \mathrm{dpi}$, then decreased, while had a slight rise at 12 dpi (Fig. 5).

\section{DTMUV localization in the spleen Immunofluorescence}

The immunofluorescence results revealed the location of XZ-2012 DTMUV in spleen at different times. It was observed that the positive reactions of the virus were detected in spleen from 2 hpi to $18 \mathrm{dpi}$ and appeared as dot-like particles, while not being detectable in the spleen at $1 \mathrm{hpi}$ or $24 \mathrm{dpi}$. The positive particles were mostly distributed in the region of white pulp from $2 \mathrm{hpi}$ to $6 \mathrm{dpi}$. The positive particles were found in the PELS and the sheathed capillary surrounded by ellipsoid and at $2 \mathrm{hpi}$, and mostly distributed in the PELS from $6 \mathrm{hpi}$ to 6 dpi. Furthermore, some positive particles were also found on the wall of the trabecular artery vessel and in the periphery of the trabecular artery at $3 \mathrm{dpi}$ and $6 \mathrm{pi}$ after infection. At $9 \mathrm{dpi}$, the positive particles were mainly observed in the red pulp. From 12 dpi to $18 \mathrm{dpi}$, the positive particles were mostly distributed in periarteriolar lymphatic sheaths (PALS) around the central artery (Fig. 6). Calculated with Image-pro plus software, the number of positive particles was increased first and then decreased after infection, reaching to the peak at 3dpi. Few particles were found at 18 dpi (Fig. 7).

\section{Tem}

The ultrastructural images revealed that the DTMUV particles were mainly present in lymphocytes and macrophages (Fig. 8). At 2hpi and 3dpi, a few virus particles without $\mathrm{E}$ protein were observed on the nucleus surface of lymphocyte and macrophage (Fig. 8a-b). At $9 \mathrm{dpi}$, the intact viral particles were present in the cytoplasm of cells with a damaged nucleus (Fig. 8c-d).

\section{Discussion}

The Flavivirus genus, in the Flaviviridae family, contains more than 70 viruses $[28,29]$. Flavivirus usually causes systemic viral injury and chronic disease after infecting humans or mammals due to their spreading through blood and causing viremia. DTMUV, as a novel discovered member of Flavivirus genus, has the same pathogenicity with other family members [26]. In this study, the DTMUV was detected in blood at $1 \mathrm{hpi}$, being present in blood until 18dpi, which indicated that the XZ-2012 could cause viremia for a long time and have a longer course of the disease.

The process of Flavivirus infection of hosts usually goes through three phases: initial infection and spread, peripheral viral amplification and neuro invasion [30]. In early infection stage, the virus mainly duplicates locally and causes viremia for the first time. Subsequently, the virus spread into the peripheral organs or tissues of the body and proliferates in large quantities and causes the second-time viremia. Eventually, the virus invades the blood-brain barrier [31, 32]. In this study, DTMUV was detected in spleen tissue from $2 \mathrm{hpi}$ and reached the highest concentration at $1 \mathrm{dpi}$ and $3 \mathrm{dpi}$, then reduced and eliminated until 24dpi. Moreover, the Flavivirus 

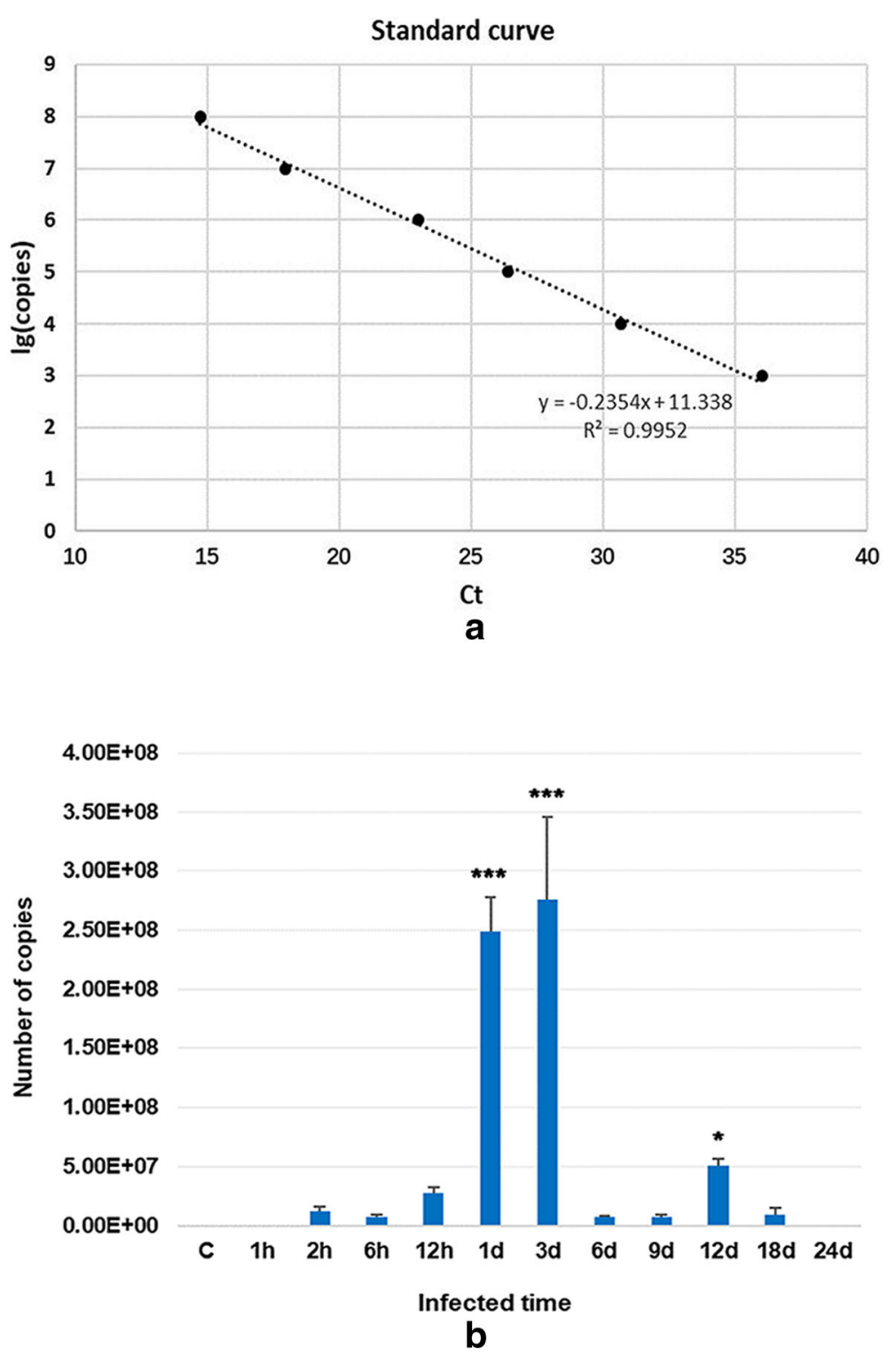

Fig. 4 Virus RT-qPCR results. a The linear formula of standard curve is $y=11.338-0.2354 x$. X-axis represents the Ct value of the detected samples, $\mathrm{Y}$-axis represents the usual logarithm of the initial concentration of samples. $\mathbf{b}$ The histogram of the mean \pm SEM of virus gene copy. The copies number of virus genes is increasing from $2 \mathrm{hpi}$, then decreases. There is a highly significant difference $(P<0.001)$ at $1 \mathrm{dpi}$ and $3 \mathrm{dpi}$ and a significant difference $(P<0.05)$ at 12 dpi compared to that of the control $(C)$

invades host cells by receptor binding and endocytosis, followed by RNA releases, replicates and assembles new virus particles [33]. According to the process and pattern of other Flavivirus infections, the dynamic distribution of virus XZ-2012 in duck spleen could be divided into several stages in our research. After the invasion, the DTMUV caused first-time viremia from $1 \mathrm{hpi}$ and accumulated in the spleen through blood circulation at $2 \mathrm{hpi}$. Afterwards, the virus concentration was increasing until 3dpi due to RNA replication and proteins assembly, reaching a replication peak between $1 \mathrm{dpi}$ to $3 \mathrm{dpi}$. After $3 \mathrm{dpi}$, the virus concentration was decreased due to the blood spreading into other organs. However, the virus concentration had a slight rise at $12 \mathrm{dpi}$ and then recovered, which might suggest the virus returned into the spleen.

The blood-spleen barrier (BSB) as the immune barrier of the spleen is present in the ellipsoid and PELS of white pulp of duck spleen. It relies on the endothelial cells of the sheathed capillary, reticular cells and fibers to block the pathogens in the ellipsoid firstly. Then the ellipsoid-associated macrophages in the PELS could trap antigens in ellipsoids and migrate into PALS through the red pulp finally [27]. The immunofluorescence revealed 


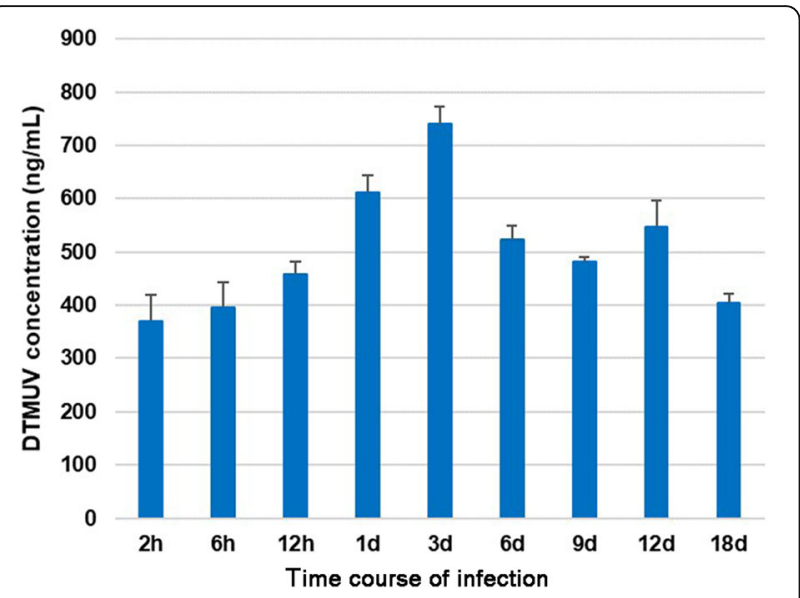

Fig. 5 The histogram of the mean \pm SEM of virus concentration. The virus concentration is increasing from $2 \mathrm{hpi}$, and has a highest value at $3 \mathrm{dpi}$, then decreases, while has a weaker rise at $12 \mathrm{dpi}$

that the DTMUV appeared in the endothelial cells of the sheathed capillary, the PELS of white pulp and the periphery of the artery at virus invasion and replication phase, which was consistent with the previous research [34]. The ultrastructural results showed that virus particles without the envelope protein were mostly accumulated at the nucleus surface of lymphocytes and macrophages. DTMUV have the tropism of immune cells such as lymphocytes and macrophages. In our recent study, we have found that DTMUV mainly caused vacuolar degeneration of macrophages and lymphocytes in PELS [35]. The structure of the barrier was destroyed. Accordingly, DTMUV might invade the spleen through BSB and replicate in the nucleus of lymphocytes and macrophages after removing the envelope protein. It was considered that lymphocytes, macrophages and endothelial cells could be vulnerable to virus invasion at this phase. At the later phase of infection, the DTMUV particles appeared in PALS around the central artery and the number of viral particles increased significantly at 12dpi compared to that of the control (C). Meanwhile, we also have found that the phagocytosis of macrophages recovered. The macrophages assembled in PELS and subsequently migrated into PALS [35]. The location was consistent with that of BSB. It was speculated that the macrophages recovered its immune function at this moment and played an important role on swallowing virus. The remaining viruses that were not killed by other organs might be returned into the spleen for immune response. However, further experiments are needed to verify how macrophages kill viruses.

Due to various adaptabilities to different host cells for culturing, the value of $\mathrm{TCID}_{50}$ was different. There is a variety of infection pathways, including subcutaneous injection, intravenous injection, peritoneal infection and cranial cavity infection. Wu et al. have found that virus titer reached the highest level at 1dpi in spleen after cultured DTMUV PTD2010 strain with duck embryo fibroblast and injected $10^{3} \mathrm{TCID}_{50}$ dose [26]. While in this experiment, BHK-21 cells were used for virus culturing and $\mathrm{TCID}_{50}$ detection. Using $10^{4} \mathrm{TCID}_{50}$ injection dose, the virus XZ-2012 strain content in spleen reached the highest level at $3 \mathrm{dpi}$. Therefore, there are probably significant differences in the pathological processes due to the different viral doses and strain.

\section{Conclusion}

In summary, this is the first study on the dynamic distribution and content of DTMUV strain XZ-2012 in infected duck spleen from invasion to elimination. It was found that DTMUV invades and replicates in the white pulp of duck spleen via invasion of BSB. It could provide information for the distribution of viruses in spleen from invasion to elimination and the relationship between virus and immune barrier.

\section{Methods \\ DTMUV strain XZ-2012 amplification}

DTMUV strain XZ-2012 was isolated and cultured in BHK-21 cells [20]. The virus, freeze-thawed three times, was injected in the allantoic cavity of 10-day specific pathogen free (SPF) duck embryos (200 $\mu \mathrm{l}$ of each). The allantoic fluid was collected after 3-4 days post injection (dpi) and detected by RT-PCR. RNA was extracted with the Trizol method (TransGen Biotech, China) and the quality was assessed using an ND-1000 spectrophotometer (Thermo, USA). RNA samples with an OD260/280 ratio between 1.8 and 2.0 were reverse transcribed into cDNA according to the manufacturer's instructions (ABM, China). Based on the E gene of XZ-2012 strain in Genbank (Accession No.: KM188953), the primers were designed, forward primer sequence 5'-GAAG CGAGCACCTACCACA-3', and reverse primer sequence 5'-CGCTGATGACCCTGTCCAT-3'. The expected amplified fragment size was $249 \mathrm{bp} .20 \mu \mathrm{l}$ reaction volume of PCR: Prime STAR Max Premix $(2 \times)$ (Takara BioTech, China) $10 \mu \mathrm{l}$, forward and reverse primer $0.25 \mu \mathrm{M}$, cDNA $1 \mu \mathrm{g}, \mathrm{ddH}_{2} \mathrm{O} 8 \mu \mathrm{l}$. The amplification condition: $95^{\circ} \mathrm{C}$ 3 min; $95^{\circ} \mathrm{C} 30$ s, $60^{\circ} \mathrm{C} 30 \mathrm{~s}, 72^{\circ} \mathrm{C} 30 \mathrm{~s}, 35$ cycles; $72^{\circ} \mathrm{C} 10$ min. The amplification products were detected by $1 \%$ agarose electrophoresis and the positive samples were preserved at $-80^{\circ} \mathrm{C}$ for further experiments.

\section{Virus titration}

Viral titers were detected by the $\mathrm{TCID}_{50}$ method $(50 \%$ tissue culture infective dose) using indirect immunofluorescence for detecting virus-induced changes in the cell culture. The BHK-21 cells were cultured in 96-well plates with high glucose DMEM (Dulbecco's modified 


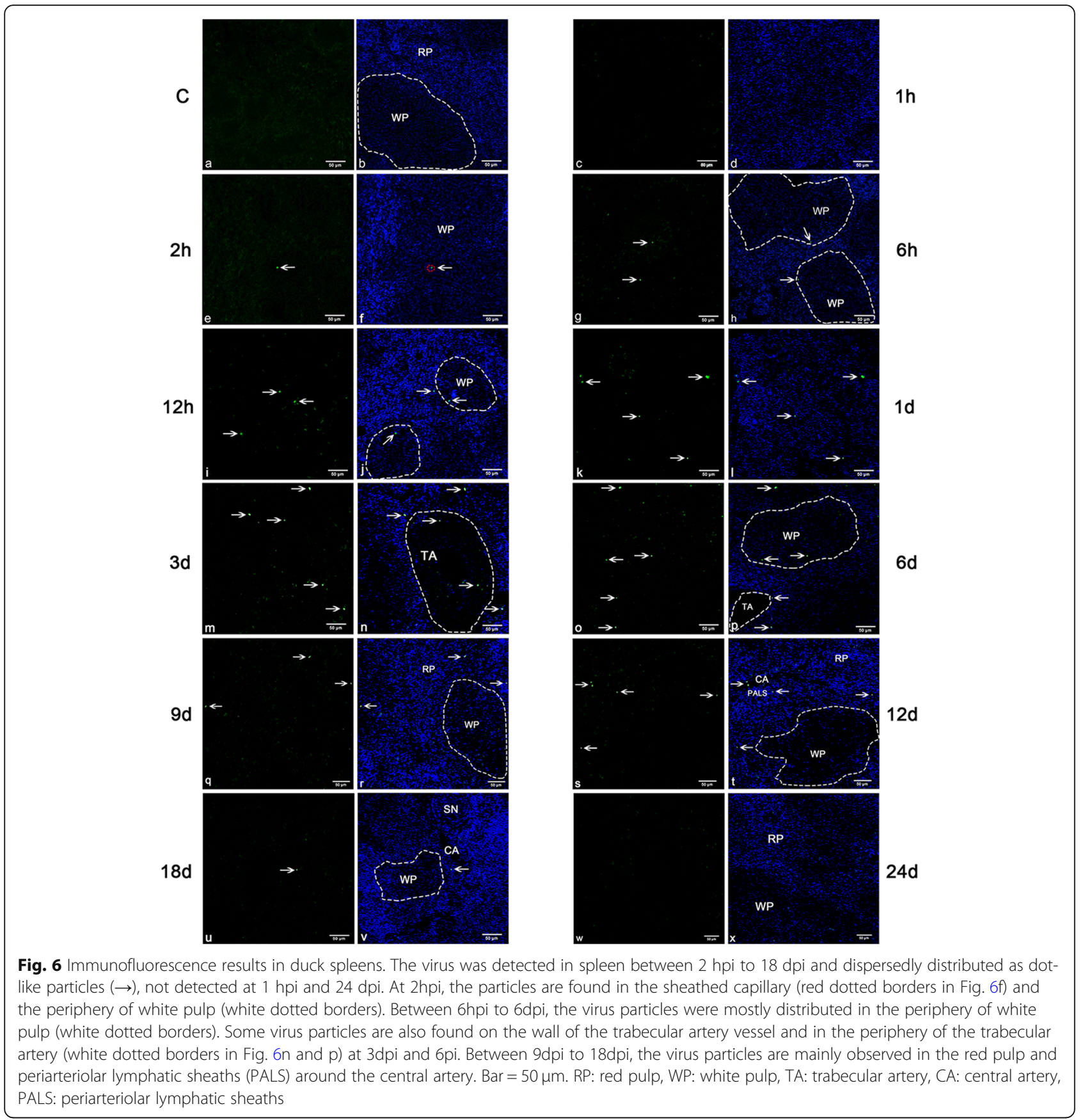

eagle medium) including $10 \%$ fetal bovine serum (FBS) and $1 \%$ penicillin-streptomycin. When the confluence was $80-90 \%$, the cells were infected with $100 \mu \mathrm{l}$ of serially diluted allantoic virus 10 -fold from $10^{-1}$ to $10^{-10}$ with serum-free DMEM (eight parallel-group of each dilution). At one-hour post infection (hpi), the supernatant was discarded. Then the cells were cultured with maintenance medium including $2 \%$ FBS and $1 \%$ penicillin-streptomycin for $48 \mathrm{~h}$ at $37^{\circ} \mathrm{C}$. After discarding the supernatant, the cells were fixed with
4\% paraformaldehyde for $30 \mathrm{~min}$ and then incubated with $0.2 \%$ Triton X-100 for 20 min to allow permeation. After blocking with $5 \%$ bovine serum albumin (BSA) for $1 \mathrm{~h}$ at $37^{\circ} \mathrm{C}$, the cells were incubated with the rabbit anti-DTMUV XZ-2012 E protein polyclonal antibody (Homemade polyclonal antibody) for $1 \mathrm{~h}$ at $37^{\circ} \mathrm{C}$. After being washed three times with phosphate-buffered saline (PBS), the cells were incubated for $1 \mathrm{~h}$ with Alexa Fluor 488 affinipure goat anti-rabbit $\operatorname{IgG}(\mathrm{H}+\mathrm{L})$ (Fcmacs Biotech Co., Ltd., China). Samples were observed 


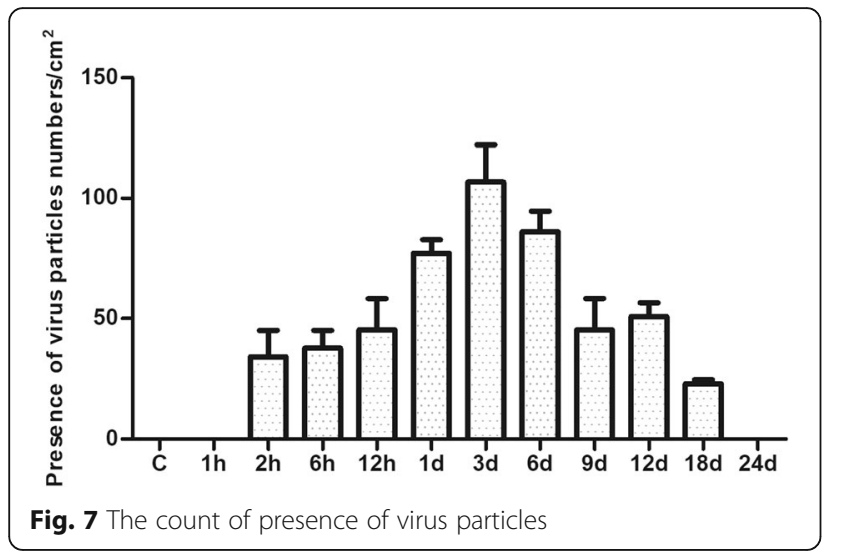

under an inverted fluorescence microscope (Olympus, Japan). The $\mathrm{TCID}_{50}$ was calculated using the method of Reed-Muench [36].

\section{Infection of experimental animals}

120 healthy egg-laying shelducks (Nanjing Zhushun Biotechnology Co., Ltd., China), weighting $1.5-2 \mathrm{~kg}$ and six months old, negative of any DTMUV and their antibody in vivo using RT-PCR and ELISA (Jiangsu Meimian industrial Co., Ltd., China) were investigated in this experiment. The ducks were divided into one control group and 11 treatment groups (10 per group). The ducks from the treatment groups were injected into leg muscle with the dose of $10^{4} \mathrm{TCID}_{50}$ of the virus and euthanized at different times $1,2,6,12 \mathrm{~h}$ and 1, 3, 6, 9, $12,18,24$ days post-infection (pi). The ducks in the control group were euthanized after injection with the same volume of $0.9 \% \mathrm{NaCl}$. The blood samples of each duck were collected and anticoagulated with $1.5 \%$ EDTA- $\mathrm{Na}_{2}$ and centrifuged to isolate the blood plasma. The spleen samples were fixed in $4 \%$ buffered paraformaldehyde and frozen in liquid nitrogen respectively. The virus levels in blood and spleen were detected by RT-PCR and ELISA.

\section{Quantitative detection of DTMUV in the spleen $R T-q P C R$ detection}

RNA of the duck spleens was extracted and reverse transcribed into cDNA. The sequence of amplified target gene was same with the amplified gene sequence of the above RT-PCR experiment (249 bp). Purified PCR products using gel extraction kit (TransGen Biotech, China) were TA cloned into the T-easy vector (FCNCS Tech
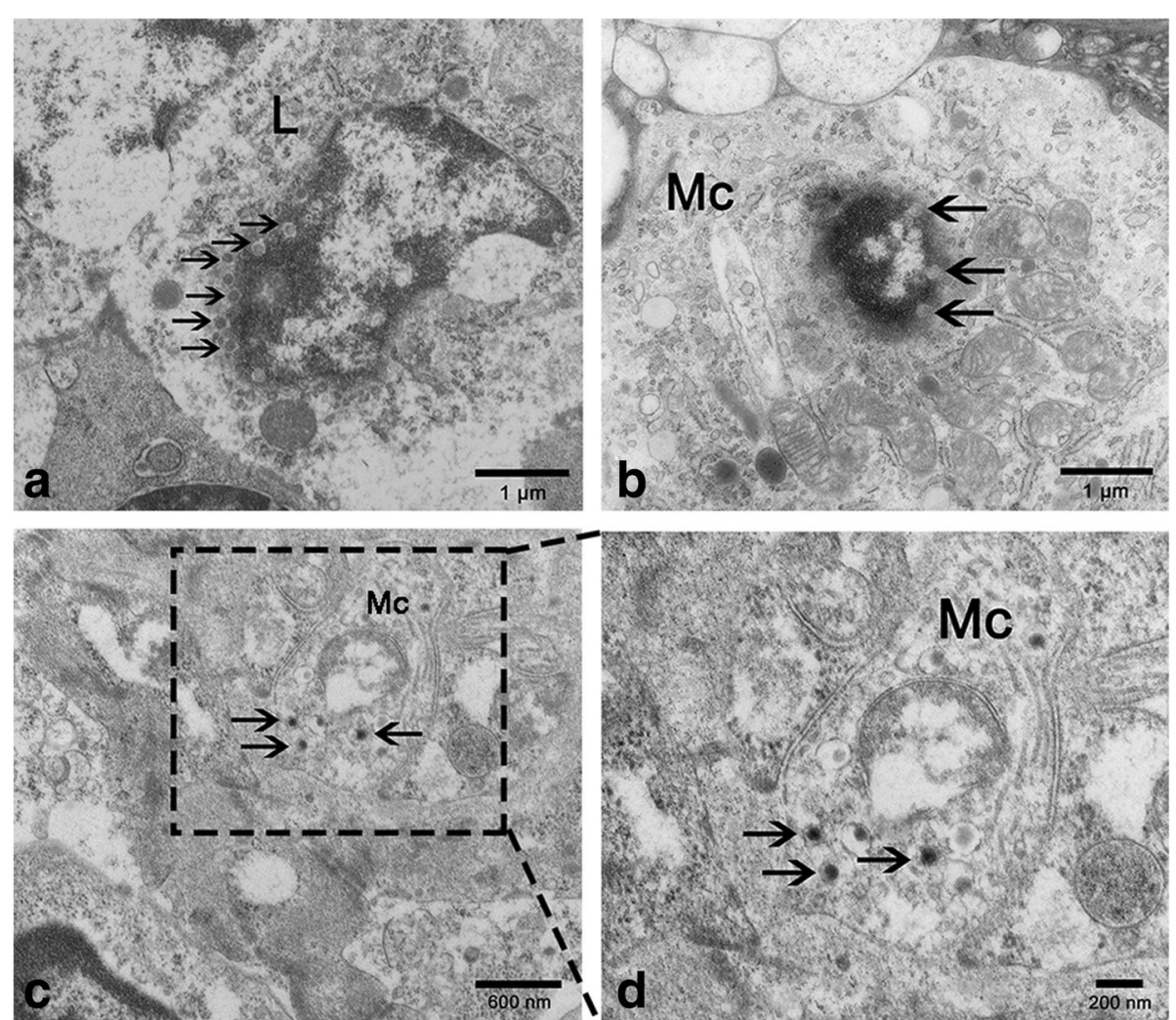

Fig. 8 The virus particles in duck spleen under TEM. a-b At $2 \mathrm{hpi}$ and $3 \mathrm{hpi}$, a few virus particles (arrow) without the envelope protein are present in the nucleus and at the surface of lymphocyte nucleus and macrophage nucleus. Bar $=1 \mu \mathrm{m}, 1 \mu \mathrm{m}$. $\mathbf{c}-\mathbf{d}$ At $9 \mathrm{dpi}$, the intact virus particles are present in the damaged macrophage. Bar $=600 \mathrm{~nm}, 200 \mathrm{~nm}$. L: lymphocyte; Mc: macrophage 
Co., Ltd., China) and transformed into the DH- $5 \alpha$ Escherichia coli competent cells (Takara BioTech Co., Ltd., China) according to the manufacturer's instructions, then cultured overnight onto LB (Luria Bertani) plates with $100 \mu \mathrm{g} / \mathrm{mL}$ ampicillin. After being cultured overnight in liquid LB medium supplemented with $100 \mu \mathrm{g} / \mathrm{mL}$ ampicillin, the ampicillin-resistant transformants were identified by PCR and DNA sequencing. Positive plasmids were isolated according to the instructions of Plasmid Miniprep Kit (TransGen Biotech, China) and quantified using the ND-1000 spectrophotometer. Plasmid copy numbers were calculated using the Avogadro's constant $\left(6.02 \times 10^{23}\right)$ and prepared according to a tenfold dilution series from $10^{1}$ copies to $10^{9}$ copies. The procedure of absolute $\mathrm{qPCR}$ was performed according to the instructions of SYBR Green MasterMix-Low ROX Kit (ABM, China) and using Applied Biosystems 7500 Real-Time PCR Systems (ABI, US). The size of the interest sequence was $157 \mathrm{bp}$ and the used primer sequences were as follows:

Forward primer: 5'-AAGCGAGCACCTACCACA-3', Reverse primer: 5' -TGCCCCATATCAACTCCAGA-3'.

Each sample was tested in triplicate. The initial virus concentrations were analyzed according to the generated standard curve.

\section{Elisa}

DTMUV in the blood and spleen homogenate supernatant was quantified by using a commercial double antibody sandwich ELISA kit (Jiangsu Meimian industrial Co., Ltd., China). The ELISA procedure was performed according to the manufacturer's instructions. The blood plasma and spleen homogenate supernatant were diluted and determined using a standard curve. There were three replicates for each sample. The optical density (OD) values were measured by microplate reader (Bio-Rad, USA).

\section{DTMUV localization in the spleen Immunofluorescence}

The spleen samples, fixed in $4 \%$ paraformaldehyde for 24-48 $\mathrm{h}$, were embedded in paraffin, and sectioned to a $3 \mu \mathrm{m}$ thickness using a Leica microtome (Germany). Briefly, after deparaffinization and washing with PBS, the antigen sections were exposed to citric acid buffer at $121{ }^{\circ} \mathrm{C}$ for $10-15 \mathrm{~min}$. Then, they were inactivated with endogenous peroxidase by covering them with $3 \%$ hydrogen peroxide for $10 \mathrm{~min}$. After being washed with PBS, the sections were blocked with 5\% BSA for $1 \mathrm{~h}$ at $37^{\circ} \mathrm{C}$ and incubated with the rabbit anti-DTMUV XZ-2012 E protein polyclonal antibody (Homemade polyclonal antibody) for $16 \mathrm{~h}$ at $4{ }^{\circ} \mathrm{C}$. After washing with PBS, the sections were incubated for $1 \mathrm{~h}$ with Alexa Fluor 488 affinipure goat anti-rabbit IgG $(\mathrm{H}+\mathrm{L})$. After washing, the sections were stained with DAPI (4', 6-diamidino-2-phenylindole) (Boster Biotech, China) for 5 min in the dark. Then the samples were covered and observed with a fluorescence microscope (Olympus DP73, Japan).

\section{Transmission electron microscopy (TEM)}

The spleen samples were cut into $1 \mathrm{~mm}^{3}$ blocks, immersed in $2.5 \%$ glutaraldehyde fixative in $0.01 \mathrm{M}$ phosphate-buffered saline (PBS; pH 7.4) at $4{ }^{\circ} \mathrm{C}$ overnight, and then submerged in $1 \%$ osmium tetroxide in the same buffer for $60 \mathrm{~min}$. The samples were dehydrated in increasing concentrations of ethyl alcohol, infiltrated with a propylene oxide-araldite mixture, and embedded in Araldite. Ultrathin sections $(50 \mathrm{~nm})$ were stained with uranyl acetate and lead citrate for 20 min each.

\section{Abbreviations}

BSA: Bovine serum albumin; BSB: Blood-spleen barrier; DMEM: Dulbecco's modified eagle medium; dpi: day post-infection; DTMUV: Duck Tembusu virus; ELISA: Enzyme-linked immunosorbent assay; FBS: Fetal bovine serum; hpi: hour post-infection; LB: Luria Bertani; OD: Optical density;

PALS: Periarterial lymphatic sheaths; PBS: Phosphate-buffered saline; PELS: Periellipsoidal lymphatic sheaths; RT-LAMP: Reverse transcription-loopmediated isothermal amplification; RT-PCR: Reverse transcription-PCR; RTqPCR: Real-time quantitative PCR; $\mathrm{TCID}_{50}$ : $50 \%$ tissue culture infective dose; TEM: Transmission electron microscopy

\section{Acknowledgements}

We thank Prof. CaoRuibing from the Key Laboratory of Animal Disease Diagnostic and Immunology, Ministry of Agriculture, Nanjing Agricultural University for providing the isolated and purified DTMUV strain XZ-2012.

\section{Funding}

This work was supported by the National Natural Science Foundation of China [grant number: 31672505 and 31872433] and Priority Academic Program for Development of Jiangsu Higher Education Institution, China. The funding had no role in the design of the study and collection, analysis, and interpretation of data and in writing the manuscript.

\section{Availability of data and materials}

The datasets used or analysed during the current study are available from the corresponding author on reasonable request.

\section{Authors' contributions}

The authors have made the following declarations about their contributions: XS designed the experiments, analyzed data and wrote the manuscript. XS performed the experimental work with the assistance of EL, TW and XW. Al, $\mathrm{AH}$ and NA gave assistance and advice of the manuscript writing. QC and PY revised the paper. All authors read and approved the final manuscript.

Ethics approval and consent to participate

The sampling procedures were approved by the Nanjing Agricultural University Veterinary College. The protocol was approved by the Science and Technology Agency of Jiangsu Province (SYXK (SU) 2010-0005).

\section{Consent for publication \\ Not applicable.}

\section{Competing interests}

The authors declare that they have no competing interests. 


\section{Publisher's Note}

Springer Nature remains neutral with regard to jurisdictional claims in published maps and institutional affiliations.

Received: 5 September 2018 Accepted: 3 April 2019

Published online: 11 April 2019

\section{References}

1. Su JL, Li SA, Hu XD, Yu XL, Wang YY, Liu PP, Lu XS, Zhang GZ, Hu XY, Liu D, et al. Duck egg-drop syndrome caused by BYD virus, a new Tembusurelated Flavivirus. PLoS One. 2011:6(3):e18106.

2. Yan PX, Zhao YS, Zhang X, Xu DW, Dai XG, Teng QY, Yan LP, Zhou JW, Ji $X W$, Zhang SM, et al. An infectious disease of ducks caused by a newly emerged Tembusu virus strain in mainland China. Virology. 2011;417(1):1-8.

3. Wan $\mathrm{CH}$, Shi SH, Cheng LF, Chen HM, Fu GH, Zhang DB, Lin F, Lin JS, Huang Y. A newly identified Flavivirus virus causing abrupt egg-laying reduction in ducks. Fujian J Agric Sci. 2010;25(6):663-6.

4. Cao ZZ, Zhang C, Liu YH, Ye WC, Han JW, Ma GM, Zhang DD, Xu F, Gao XH, Tang $Y$, et al. Tembusu virus in ducks, China. Emerg Infect Dis. 2011;17(10):1873-5

5. Teng Q, Yan P, Zhang X, Yan L, Li Z. A novel flavivirus causing duck egg drops and death. Chin J Anim Infect Dis. 2010;18(6):1-4.

6. Zhang W, Chen S, Mahalingam S, Wang MS, Cheng AC. An updated review of avian-origin Tembusu virus: a newly emerging avian Flavivirus. J Gen Virol. 2017;98(10):2413-20.

7. Wang JM, Liu WT, Meng G, Zhao KN, Gu JY, Chen PY, Cao RB. Isolation and genome characterization of a novel duck Tembusu virus with a 74 nucleotide insertion in the 3 ' non-translated region. Avian Pathol. 2015:44(2):92-102.

8. Chen CT. Research on the effect of duck Tembusu virus infection on immune function of duck. Fuzhou: Fujian Agriculture and Forestry University; 2014.

9. Luo L, Wen GY, Tang J, Luo QP, Wang HL, Ai DY, Zhang RR, Gou M, Shao HB. Histopathological observation of ducks infected naturally with duck Flavivirus. Prog Vet Med. 2012;33(2):129-32.

10. Yan Z, Shen H, Wang Z, Lin W, Xie Q, Bi Y, Chen F. Isolation and characterization of a novel Tembusu virus circulating in Muscovy ducks in South China. Transbound Emerg Dis. 2017;64(5):E15-7.

11. Wan $\mathrm{CH}$, Huang Y, Fu GH, Shi SH, Cheng LF, Chen HM. Complete genome sequence of avian Tembusu-related virus strain WR isolated from white Kaiya ducks in Fujian, China. J Virol. 2012;86(19):10912.

12. Yun T, Ye WC, Ni Z, Zhang DB, Zhang C. Identification and molecular characterization of a novel flavivirus isolated from Pekin ducklings in China. Vet Microbiol. 2012;157(3-4):311-9.

13. Chen $S L$, Chen SY, Wang S, Lin FQ, Jiang B, Cheng XX, Huang MQ, Zhu XL, $\mathrm{Li}$ ZL. Isolation and identification of new Flaviviruses causing reduction on egg-laying in chicken. Fujian J Agric Sci. 2011;26(2):170-4.

14. Zhang DJ, Shen XH, Zhao RH, D Y HXM, Pan XC, Hou HY, Zhou XL, Zhu CM. Pathogenicity study of duck Tembusu virus in laying hens. China Poultry. 2015;37(13):13-7.

15. Ti JF, Zhang L, Li ZJ, Zhao DD, Zhang Y, Li F, Diao YX. Effect of age and inoculation route on the infection of duck Tembusu virus in goslings. Vet Microbiol. 2015;181(3-4):190-7.

16. Yun T, Zhang DB, Ma XJ, Cao ZZ, Chen L, Ni Z, Ye WC, Yu B, Hua JG, Zhang $Y$, et al. Complete genome sequence of a novel Flavivirus, duck Tembusu virus, isolated from ducks and geese in China. J Virol. 2012;86(6):3406-7.

17. Huang XM, Han KK, Zhao DM, Liu YZ, Zhang JF, Niu HM, Zhang KN, Zhu JN, Wu DM, Gao L, et al. Identification and molecular characterization of a novel flavivirus isolated from geese in China. Res Vet Sci. 2013;94(3):774-80.

18. Li S, Li XX, Zhang LJ, Wang YY, Yu XL, Tian KG, Su WL, Han B, Su JL. Duck Tembusu virus exhibits neurovirulence in BALB/c mice. Virol J. 2013:10:260.

19. Liu ZL, Ji YH, Huang XH, Fu YG, Wei JZ, Cai XP, Zhu QY. An adapted duck Tembusu virus induces systemic infection and mediates antibodydependent disease severity in mice. Virus Res. 2013;176(1-2):216-22.

20. Wang Y, Wang JM, Cao RB. Isolation and gene variation character of duck Tembusu virus strain XZ-2012. J Nanjing Agric Univ. 2015;38(3):446-52.

21. Yin XC, Lv R, Chen XD, Liu M, Hua RH, Zhang Y. Detection of specific antibodies against Tembusu virus in ducks by use of an E protein-based enzyme-linked immunosorbent assay. J Clin Microbiol. 2013;51(7):2400-2.

22. Jiang $T$, Liu J, Deng YQ Su $\lrcorner$, Xu $\perp$, Liu ZH, Li XF, Yu XD, Zhu SY, Gao GF, et al. Development of RT-LAMP and real-time RT-PCR assays for the rapid detection of the new duck Tembusu-like BYD virus. Arch Virol. 2012:157(12):2273-80

23. Carson PJ, Konewko P, Wold KS, Mariani P, Goli S, Bergloff P, Crosby RD. Long-term clinical and neuropsychological outcomes of West Nile virus infection. Clin Infect Dis. 2006;43(6):723-30.

24. Garcia G, Gonzalez N, Perez AB, Sierra B, Aguirre E, Rizo D, Izquierdo A, Sanchez L, Diaz D, Lezcay M, et al. Long-term persistence of clinical symptoms in dengue-infected persons and its association with immunological disorders. Int J Infect Dis. 2011;15(1):E38-43.

25. Kato N, Sejima H, Ueda Y, Mori K, Satoh S, Dansako H, Ikeda M. Genetic characterization of hepatitis C virus in long-term RNA replication using Li23 cell culture systems. PLoS One. 2014;9(3):e91156

26. Wu L, Liu J, Chen $P$, Jiang Y, Ding L, Lin Y, Li Q, He X, Chen Q, Chen H. The sequential tissue distribution of duck Tembusu virus in adult ducks. Biomed Res Int. 2014:2014:703930.

27. Sun XJ, Liu EX, Wang TZ, Zhang Q, Yang P, Ahmed N, Zhao QY, Chen QS. The novel histological evidence of the blood-spleen barrier in duck (Anas platyrhynchos). Histol Histopathol. 2019;34(1):33-45.

28. King NJC, Getts DR, Getts MT, Rana S, Shrestha B, Kesson AM. Immunopathology of flavivirus infections. Immunol Cell Biol. 2007;85(1):33-42.

29. Mukhopadhyay S, Kuhn RJ, Rossmann MG. A structural perspective of the Flavivirus life cycle. Nat Rev Microbiol. 2005:3(1):13-22.

30. Suthar MS, Diamond MS, Gale M Jr. West Nile virus infection and immunity. Nat Rev Microbiol. 2013;11(2):115-28.

31. Samuel MA, Diamond MS. Pathogenesis of West Nile virus infection: a balance between virulence, innate and adaptive immunity, and viral evasion. J Virol. 2006;80(19):9349-60.

32. Sejvar JJ, Haddad MB, Tierney BC, Campbell GL, Marfin AA, Van Gerpen JA, Fleischauer A, Leis AA, Stokic DS, Petersen LR. Neurologic manifestations and outcome of West Nile virus infection. JAMA. 2003;290(4):511-5.

33. Rodenhuis-Zybert IA, Wilschut J, Smit JM. Dengue virus life cycle: viral and host factors modulating infectivity. Cell Mol Life Sci. 2010;67(16):2773-86.

34. Wu L. Pathogenesis and replication kinetics of duck Tembusu virus. Nanjing: Nanjing Agricultural University; 2014.

35. Sun X, Li W, Liu E, Huang H, Wang T, Wang X, Shi Y, Yang P, Chen Q. In vivo cellular and molecular study on duck spleen infected by duck Tembusu virus. Vet Microbiol. 2019:230:32-44.

36. Reed $\amalg$, Muench $H$. A simple method of estimation of fifty percent endpoint. Am J Epidemiol. 1938:27(3):493-7.

Ready to submit your research? Choose BMC and benefit from:

- fast, convenient online submission

- thorough peer review by experienced researchers in your field

- rapid publication on acceptance

- support for research data, including large and complex data types

- gold Open Access which fosters wider collaboration and increased citations

- maximum visibility for your research: over $100 \mathrm{M}$ website views per year

At BMC, research is always in progress.

Learn more biomedcentral.com/submission 